\title{
OS DESAFIOS CONTEMPORÂNEOS DO IMPÉRIO ESTATAL EM FACE DAS ORGANIZAÇÕES INTERNACIONAIS: VIOLAÇÃO DA SOBERANIA FRENTE À LEGITIMIDADE DE PROTEÇÃO AO DIREITO DE PAZ
}

LOS DESAFÍOS CONTEMPORÁNEOS DEL IMPERIO ESTATAL ANTE LAS ORGANIZACIONES INTERNACIONALES: VIOLACIÓN DE LA SOBERANIA FRENTE A LA LEGITIMIDAD DE PROTECCIÓN A LO DERECHO DE PAZ

Luiz Fernando Vescovi* Anatieli Aparecida Fiabane ${ }^{* *}$

Resumo: O presente ensaio acadêmico tem por objetivo expor os atuais entraves existentes entre o domínio clássico do poderio estatal e a atuação das organizações internacionais acerca da dicotomia entre a tentativa, por parte dos estados-nação, de se resguardar a tradicional acepção do instituto da soberania e a moderna atividade executada pelas organizações de cunho internacional que almejam, pois, a proteção máxima do direito de paz, demonstrando as dificuldades de se encontrar um limiar comum para que se alcance a satisfação de ambos os segmentos ideológicos, expondo-se, à luz dos postulados elementares dos direitos humanos e do direito humanitário, as principais consequências (políticas e econômicas) que decorrem desta oposição.

Resumen: Este ensayo académico tiene como objetivo exponer las barreras existentes actualmente entre el dominio clásico del poder del Estado y las actividades de las organizaciones internacionales sobre la dicotomía entre el intento, por parte de los Estados-nación, de proteger el sentido tradicional del instituto de la soberanía y la moderna actividad realizada por las organizaciones de carácter internacional que tienen como objetivo,

\footnotetext{
* Universidade do Oeste de Santa Catarina, Brasil.

E-mail: luizfernandovescovi@bol.com.br

** Damásio Educacional, Brasil.

E-mail: anatielifiabane@gmail.com

Recebido: 22/11/2016. Aceito: 16/02/2017.
} 
por tanto, la máxima protección del derecho a la paz, lo que demuestra la dificultad de encontrar un umbral común para lograr la satisfacción de ambos los segmentos ideológicos, exponiéndose, a la luz de principios básicos de los derechos humanos y el derecho humanitario, las principales consecuencias (políticas y económicas) que surgen de esta oposición.

Palavras-chave: Soberania, Intervenção, Organizações internacionais, Direitos humanos, Direito de paz

Palabras clave: Soberanía, Intervención, Organizaciones internacionales, Derechos humanos, Derecho de paz

\section{INTRODUÇÃO}

Tem-se que desde os idos do surgimento da civilização estatal, a política é o elo primordial entre nações, sobretudo do ponto de vista da manutenção da ordem interna, como sendo um elemento umbilicalmente ligado à sociedade e formado por fatores inconstantes que a condicionam e a modificam, como por exemplo, as forças econômicas e religiosas que, consequentemente, acarretam em reflexos na esfera do Direito Internacional Público. Levando-se em conta que certas escolhas e/ou decisões tomadas por determinados Estados podem chegar a ter alcance de envergadura universal, e que estas podem não ser imediatamente aceitas ou aprovadas pela comunidade internacional em geral, vislumbrou-se a necessidade da criação de estruturas supranacionais chamadas de organizações internacionais que, por suas atuações institucionais, concentraram, desde a sua gênese, os seus esforços na preservação da paz, fomentando, neste ínterim, a solução pacífica de conflitos as quais, por sua vez, podem se apresentar como sendo de consequência natural-incidental de tais decisões, proporcionando, deste modo, significativos intermediadores para a aferição da segurança coletiva.

Entretanto, em meio a todo o debate político de ação internacional, com fins na proteção de direitos de cunho global, releva-se uma questão pertinente, eis que o cerne da questão, por certo, é a eventual solução pacífica, porém a dificuldade maior para se obter o êxito esperado neste tipo de operação está justamente em delimitar a atuação política dos Estados considerados potências mundiais, bem como das organizações frente às intervenções militares que indiquem pretensões humanitárias e, sobretudo, de garantir a permanência da soberania nacional dos países que enfrentam situações desta natureza (intervenções). Neste sentido, faz-se pensar, constantemente, em mecanismos institucionais e regulatórios internacionais para tal, tomando-se por base uma análise especificamente cultural, para que, deste modo, se chegue 
a um delimitador comum acerca da legitimidade das intervenções humanitárias.

Sabe-se que, muito embora a soberania siga sendo o princípio dominante das relações entre Estados, a internacionalização dos direitos humanos possibilitou o surgimento de ações próprias que tem por finalidade a sua respectiva salvaguarda, como é o caso da prática da intervenção humanitária. No entanto, tratar do tema em específico não é questão fácil, eis que envolve vultosos debates de ordem cultural, econômica e governamental, razão pela qual a indeterminação acerca das normas internacionais que autorizam tal prática ainda permanece sem consenso perante a comunidade internacional.

Neste norte, o objetivo central do presente ensaio científico é investigar a problemática sobre a ausência de unanimidade global sobre as normas alusivas à intervenção humanitária, esperando-se, com isso, poder contribuir para o debate estrutural-normativo relativo à temática proposta, demonstrando, pois, os principais pontos de divergência entre os interesses dos Estados e das organizações internacionais que agem como interventores nestas situações, além de trazer a lume a verdadeira essência de se intervir para proteger aos mais necessitados em eventual estado de conflito armado: os cidadãos nacionais.

Não obstante, o que se observa, atualmente, é que, na prática, o mecanismo acima referendado se apresenta deveras imperfeito no tocante à promoção dos direitos humanos e na proteção da paz, julgandose, portanto, como indispensável a discussão acadêmica a respeito. Neste sentido, a pesquisa ora apresentada restou elaborada a partir de uma reflexão de cunho filosófico-doutrinária acerca da necessidade de normatização e da adequada aplicabilidade do instituto da intervenção humanitária, pois se sabe, também, que o mesmo é categoricamente imprescindível para o progresso e a preservação do homem enquanto sociedade global e que deve ser exaustivamente aprimorado para se tornar potencialmente efetivo em situações de crise em que atos abomináveis atentem contra a dignidade da pessoa humana.

\section{ORIGEM, FORMAČ̃̃O E ASPECTOS CONCEITUAIS ACERCA DA SOBERANIA NAĆIONAL}

A história é uma ciência em constante transformação, que desenha o tempo explicando as mudanças sobrevindas ao longo dos séculos, apresentando diversos estruturalismos que resultam em relatos específicos e relevantes para a ocorrência de determinados fenômenos, tal como acontece com o elemento soberania, cujos estudos comportam evoluções gradativas sobre o seu entendimento, o que dificulta, sobremaneira, o consenso em relação à origem do termo. Alguns estudiosos, no entanto, afirmam que a referida expressão tem sua 
procedência no latim medieval, advindo da palavra “(...) superanus e, mais recentemente, do francês - souveraineté, ou ainda super + omnia, supremitas, ou simplesmente superior". O que se verifica é que, apesar da imprecisão a respeito da ascendência terminológica, o conceito de soberania, com o passar dos tempos, se tornou de excepcional importância política, marcada como uma característica fundamental do Estado e de sua constituição.

De pronto, constata-se que, em sentido restrito e conforme a sua acepção moderna, o vocábulo em questão aparece no final do século XVI, associado à formação plena da estrutura estatal ${ }^{2}$, embasado na unificação e na concentração do poder no próprio Estado, sujeito único e exclusivo da política ${ }^{3}$. Contudo, é apenas com a chegada da Revolução Francesa (1789-1799) e dos movimentos sociais pregando ideais revolucionários que acabou por culminar para que o padrão governamental daquele momento viesse a expressar visível e significativa alteração, uma vez que o tradicional conceito de Estado patrimonial ${ }^{4}$ havia sido categoricamente substituído pelo de soberania da nação. Este período histórico ficou marcado como sendo o momento em que o cidadão deixou de ser o "súdito" e adquiriu a consciência de pertencer a um determinado grupo social, encontrando-se, pela primeira vez, na definição montada em torno do que seria, efetivamente, a nacionalidade ${ }^{5}$.

No decorrer de todo o embate ideológico travado pela burguesia contra a monarquia absolutista, a ideia de soberania popular ${ }^{6}$, desenvolvida por Rousseau, começou a caminhar convergente com a de soberania nacional, possibilitando, de mais a mais, para que, no século XIX, se consagrassem bases filosóficas sólidas para justificar a expressão poder político, tornando-se, no século posterior, oficialmente incorporada à doutrina jurídica como nota característica para a constituição da acepção

1 FILOMENO, José Geraldo Brito. Manual de teoria geral do Estado e ciência política. $5^{\mathrm{a}}$ ed. Rio de Janeiro: Forense Universitária, 2003, p. 135.

2 É necessário o estabelecimento de elementos indispensáveis para que o Estado possa ser reconhecido enquanto sujeito de Direito Internacional, quais sejam: a) população (nacionais e estrangeiros); b) território (definido) e; c) governo (deve ser efetivo e estável). Todavia, temse que o principal elemento para construir um Estado, na sua condição plena, é a soberania. MELLO, 2004, p. 355.

3 BOBBIO, Norberto; MATTEUCCI, Nicola; PASQUINO, Gianfranco. Dicionário de política. $11^{a}$ ed. Brasília: Editora UnB, 1998, p. 1179.

4 Segundo Antonio Frederico Zancanaro (1994, p. 20-21), “(...) o Estado Patrimonial convertese em domínio privado do monarca, uma extensão de sua casa real, de sua família e de seu patrimônio pessoal".

5 BOBBIO; MATTEUCCI; PASQUINO. Op. cit., p. 71.

6 De acordo com este princípio “(...) o Estado que se constitui num domínio pessoal do príncipe é substituída pela ideia de que o Estado pertence ao povo, definido como um conjunto de cidadãos e não de súditos". Íbid, p. 800.

7 Darcy Azambuja (2008, p. 94) assim explica: “(...) significa que a nação possui uma vontade superior e diferente da vontade dos indivíduos que a formam, pois que soberania, em análise, quer dizer uma vontade que se determina por si mesma, não depende de nenhuma vontade ou força exterior a ela". 
de Estado ${ }^{8}$. Éneste contexto sociológico, então, que se moldam os primeiros conceitos teóricos acerca do termo soberania, os quais repercutem na vida política e societária até os dias de hoje como verdadeiro símbolo da nãointervenção de um Estado sobre o outro.

Constata-se, portanto, que a terminologia sobre o postulado em questão foi o alicerce maior que propiciou inaugurar o chamado Estado Moderno (séculos XV a XVIII), especialmente com o esplendor da Revolução Francesa, que trouxe os primeiros indícios de definição de soberania como sendo o “(...) poder monolítico, absoluto, não podendo haver outro que a ele se equipare, ou então que venha abalar sua supremacia inconteste" . É, pois, a soberania a expressão máxima do poder estatal. Contudo, há que se ponderar que, embora seja ela um poder incontestável, deve, logicamente, expressar pré-estabelecimento de seus limites, a fim de satisfazer as necessidades da população do Estado, e, assim, assegurar a consecução do bem comum, que vem a ser, em linhas gerais, a realização global dos direitos do ser humano.

No entanto, é preciso frisar que as restrições da soberania não devem extrapolar os limites de tolerância que se julga paulatinamente aceitável no âmbito das relações internacionais, com o propósito de se adentrar na jurisdição interna dos países através de ingerências supérfluas, razão pela qual existe, prioritariamente, o diálogo e as aproximações diplomáticas como pontos norteadores para a solução pacífica de possíveis conflitos entre Estados.

No aspecto interno, pode-se dizer que a origem da soberania encontra-se alinhada à vontade nacional em razão do que evidenciava Thomas Hobbes ao enfatizar que é o povo quem confere a soberania ao Estado mediante o consentimento reunido em Assembleia, marcando-se, dessa maneira, a fonte do contrato celebrado entre o governo e os seus respectivos súditos. Partindo da premissa teórica hobbesiana, então, o filósofo Emer de Vatte ${ }^{10}$ destaca o fato de que são os homens que formam a sociedade, e dessa união é que surge a consequente carência de se constituir uma autoridade pública, destinada a orientar esta associação, porém, o comando nacional reside na própria soberania, eis que tal direito pode ser confiado à diferentes mãos, e acabam facilmente sendo alteradas, no entanto, a única que persiste ad aeternum é a própria soberania.

É preciso, ainda, fazer referência que "no contexto internacional, a soberania do Estado significa na realidade que ele não está sujeito a leis que lhe sejam impostas por uma autoridade supra-estabelecida, dotada do monopólio da força (...)"'11. Ademais disso, será também considerada soberana, para efeitos políticos e doutrinários, "toda Nação que se

8 DALLARI, Dalmo de Abreu. Elementos de teoria geral do Estado. 30 a ed. São Paulo: Saraiva, 2011, p. 85.

9 FILOMENO, Op. cit., p. 134.

10 VATTEL, Emer de. O direito das gentes. Brasília: Editora UnB, 2004, p. 101.

11 BOBBIO; MATTEUCCI; PASQUINO. Op. cit., p. 1089. 
governa por si mesma, sob qualquer forma que seja, sem dependência de nenhum estrangeiro, é um Estado soberano. Os seus direitos são naturalmente os mesmos dos demais Estados"12. Por isso, não se pode admitir que os contrastes que advém da vivência internacional sejam decididos a partir da vontade de um poder dominador, do ponto de vista sócio-político, o qual impõe ao ordenamento jurídico interno dos Estados condutas julgadas, por aquele, como universalmente aceitáveis, mas que, em verdade, comportam a pretensão de minorias estatais entendidas como potências nacionais - que concentram, por sua vez, o poderio econômico mundial.

\section{SOBERANIA E DIREITOS HUMANOS: A LEGITIMIDADE DE INTERVENÇÃO EM TEMPOS DE CRISE HUMANITÁRIA}

Em épocas mais remotas da história, não se tinha, por parte dos povos, o conhecimento a respeito do sistema de equilíbrio (político e jurídico) entre Estados que se aplica atualmente, tendo em vista que, naquele tempo, a ordem era estabelecida pela simples capacidade de se governar internamente, além do que os conflitos somente guerras ocorriam em fronteiras externas, e de modo pontual, e a paz era observada através do alcance do poder imperial ${ }^{13}$. Com o transcurso do tempo as delimitações fronteiriças foram efetuadas de maneira a servir aos interesses dos grandes territórios e de seus governantes, bem como de toda a associação de pessoas envolvida em questões atreladas à situação transcorrente.

Observa-se que, hoje em dia, nenhum governo admite manter um exército e/ou armas para satisfazer seus desejos de conquista. $\mathrm{O}$ argumento, neste caso, é de que o fim a que se destinam é pura e simplesmente de defesa do próprio território nacional. A afirmação gira em torno de que a luta é justa e moralmente correta quando amparada na legítima defesa, porém, quando o vizinho também se arma em busca proteção, os meios, então, se tornam "imorais". "Assim se colocam atualmente os Estados: cada qual pressupõe a má disposição do vizinho e a boa disposição própria" ${ }^{14}$. Ambos os lados estão, portanto, salvaguardando os seus pontos de vista e os interesses respectivos. É uma postura que enseja controvérsias argumentativas as mais distintas possíveis.

Entretanto, há que se recordar que as grandes nações somente emergiram em decorrência das guerras, pois, ao ingressarem no sistema de alianças para lutar, foram suficientemente capazes de sustentar suas

12 VATTEL, Emer de. Op. cit., p. 16.

13 KISSINGER, Henry. Ordem mundial. Rio de Janeiro: Objetiva, 2015, p. 18.

14 NIETZSCHE, Friedrich. Humano, demasiado humano: um livro para espíritos livres. São Paulo: Companhia das Letras, 2008, p. 214. 
próprias forças militares, além de financiar os demais aliados, além do fato de que, em períodos de paz, conseguiram conservar as relações de forças, bem como assegurar a manutenção dos pactos e das promessas feitas durante a campanha ${ }^{15}$.

Hoje os Estados são conscientes de que estão atrelados - uns aos outros - por certos valores e interesses em comum, o que os tornam vinculados a determinadas regras no tocante ao seu interrelacionamento, como por exemplo, o de respeitar a independência de cada um, de honrar os acordos e de restringir o uso recíproco da força, ademais de cooperar para o funcionamento de instituições, tais como a diplomacia, os costumes e as convenções de guerra ${ }^{16}$.

No momento histórico presente, os países trabalham em conjunto com foco no objetivo de condenar a violência, a qual se convencionou chamar de terrorismo ${ }^{17}$. Destaque é atribuído às sociedades ocidentais que exibem tamanha sensibilidade perante as diferentes formas de violação humana a ponto de esboçar simpatia humanitária para com as vítimas, mobilizando uma série de mecanismos destinados a simplesmente estigmatizar a ferocidade da violência com a chancela de "má". Para tanto, tal atitude social não chega a sucumbi-la, mas apenas colabora com o processo de tornar invisíveis as formas elementares que fazem a brutalidade aflorar na vida social ${ }^{18}$.

Vê-se, portanto, que a humanidade está passando por uma remodelação jurídica, na qual se constata uma nova interação entre o direito interno das nações e a ordem internacional em sentido amplo, objetivando, deste modo, obter o maior complemento jurídiconormativo um do outro. O reconhecimento do valor da dignidade da pessoa humana passou a ser protegido em nível supranacional, e a soberania, hoje, é analisada por um prisma mais relativo, cuja principal função é a proteção do Estado que a ostenta ${ }^{19}$.

Em vista disso, então, considera-se aceitável a interferência advinda externamente quando o propósito é resguardar os direitos humanos, e o meio adequado utilizado para tal é a intervenção humanitária. Primeiramente, há que se partir da ideia de intervenção pura e simples, para, assim, se chegar ao mérito sobre qual modalidade

15 GRAMSCI, Antonio. Maquiavel, a política e o Estado moderno. $7^{\text {a }}$ ed. Rio de Janeiro: Civilização Brasileira, 1989, p. 193.

16 BULL, Hedley. A sociedade anárquica: um estudo da ordem na política mundial. São Paulo: Clássicos IPRI, 2002, p. 19.

17 “A palavra 'terrorismo' é conhecida como toda atividade criminal de caráter violento que se realiza com o fim de conseguir uma série de objetivos políticos". Disponível em: <http:// conceitos.com/terrorismo>. [acesso em: 22 set. 2016].

18 ZIZEK, Slavoj. Violência: seis reflexões laterais. São Paulo: Boitempo, 2014, p. 131.

19 ROSA, Leonardo Sérgio Cesar Lopes Moreira. "Poder constituinte controlador: uma solução diplomática aos conflitos de grandes proporções”. Conteúdo Jurídico. [acesso em: 21 fev. 2016]. Disponível em: <http://www.conteudojuridico.com.br/artigo,poder-constituintecontrolador-uma-solucao-diplomatica-aos-conflitos-de-grandes-proporcoes, 46572 .html> 
será adequadamente aplicada para se obter os resultados almejados da melhor maneira possível. Neste sentido, revela-se difícil a sua conceituação, levando-se em conta que o posicionamento doutrinário ainda não está completamente pacificado. Alguns autores defendem que a intervenção significa absoluta ingerência em assuntos internos e externos de uma nação, enquanto que outros analistas limitam seu entendimento a respeito à apenas assuntos de caráter interno. Tomando por base uma das correntes em apreço, e para fins de compreensão do instituto em tela, traslada-se a formulação teorética de Celso D. de Albuquerque Mello, a saber:

A intervenção ocorre quando um Estado, ou grupo de Estados, interfere, para impor a sua vontade, nos assuntos internos ou externos de outro Estado soberano ou independente com o qual existem relações pacíficas e sem o seu consentimento, com a finalidade de manter ou alterar o estado das coisas ${ }^{20}$.

Entrementes, reputa-se a ressalva efetuada pelo próprio autor, em seus escritos, quando defende não haver validade, para o campo do Direito Internacional Público, a intervenção efetuada em período de guerra civil, mesmo quando solicitada pelo governo local. Assim dispõe a lição a respeito:

(...) o consentimento é irrelevante para legitimar a intervenção, vez que existe um dever de todo e qualquer governo ou mesmo de revoltosos de não solicitarem intervenção de Estado estrangeiro. Enfim, haveria uma violação do princípio de autodeterminação ${ }^{21}$.

Deste modo, deve-se recordar que, muito embora a regra internacional seja pela não-intervenção na soberania dos Estados, os costumes internacionais apontam a existência de possibilidades de uma nação vir a intervir sobre outra, sendo que dentre as situações particularmente concebíveis destacam-se as seguintes: I) quando a intervenção é realizada mediante convite do Estado que está sofrendo a interferência; II) quando se tem por objeto a defesa de um Estado ameaçado ou; III) quando se tem por finalidade a proteção dos direitos de pessoas estrangeiras que estão sob a autoridade de um governo opressivo. Alguns estudiosos afirmam que esta última modalidade é a que ensejou a origem da chamada intervenção humanitária, tendo sido bastante utilizada durante o Século XIX, quando os países europeus intervieram em nome dos cristãos que estavam sendo perseguidos e

20 MELLO, Celso D. de Albuquerque. Curso de direito internacional público. 15a ed. Rio de Janeiro: Renovar, 2004, p. 492.

21 Íbid., p. 492. 
oprimidos pelo Império Otomano (1299-1923) 22 .

Sabe-se, desde logo, que toda qualquer revolta legítima, deflagrada por um povo que rejeita, em absoluto, o poder opressivo do chamado "tirano" é, sim, considerado e reconhecido como um direito político. Todavia, é preciso asseverar que ainda que uma revolta desta natureza esteja acobertada pelo mando do Direito, a mesma acaba por se tornar interpretativamente injusta na medida em que os súditos reivindiquem seus direitos de maneira bastante incisiva a ponto, inclusive, de haver embates corporais com efetivas violações físicas, o que ensejaria até mesmo uma ocasional intervenção humanitária, dadas as devidas condições e a gravidade da ocasião. Em convergência ao pensamento kantiano, se casualmente viesse a ocorrer tal situação, ninguém (nem governo nem nacionais) poderia queixar-se de eventuais injustiças, isto é, teria de se suportadas as mais duras penas decorrentes da governança imposta, pautada na legitimidade representativa e política do próprio governante ${ }^{23}$.

Não obstante, retornando ao período histórico do Século XVIII, algumas minorias sociais já observavam que todo o indivíduo, independente da qualificação profissional ou classe pertencente, desde o nascimento, possuía, de antemão, “(...) certos direitos políticos fundamentais, os chamados direitos do homem e do cidadão, e que, a rigor, estes direitos comuns a todos são os únicos existentes" ${ }^{24}$. Esta premissa, na condição de um teorema, fez com que, aos poucos, a própria sociedade começasse a praticar tal ideal, impondo e reclamando, sob a égide das legislações democráticas, que fossem observados os aludidos direitos intrínsecos ao ser humano. A recente inovação, então, forçou profundamente para que houvesse um verdadeiro avanço aos debates relativos à proteção dos direitos humanos.

A concepção contemporânea de direitos humanos, na esfera internacional, veio como fruto dos movimentos pós-Segunda Guerra Mundial, trazendo resposta às atrocidades e aos horrores cometidos durante o período do Nazismo (1933-1945), momento histórico este em que o Estado se tornou, pois, o maior violador da pessoa humana, enviando 18 milhões de pessoas para campos de concentração, e que resultou, lastimosamente, na morte de 11 milhões, sendo 6 milhões de judeus, além de comunistas, homossexuais, ciganos, dentre outros ${ }^{25}$. O legado maior do Holocausto, no entanto, foi o de estabelecer parâmetros para a fundada internacionalização dos direitos humanos, gerando, na coletividade mundial, uma consciência

22 SPIELER, Paula Bartolini. "A indeterminação do conceito de intervenção humanitária: reflexo no caso Timor Leste". [Dissertação de Mestrado em Relações Internacionais]. Pontifícia Universidade Católica do Rio de Janeiro, Rio de Janeiro, 2007.

23 KANT, Immanuel. A paz perpétua: um projeto filosófico. Covilhã: Universidade da Beira Interior, 2008, p. 47.

24 ORTEGA Y GASSET, José. A rebelião das massas. Brasília: Ruriak Ink, 2013, p. 49.

25 PIOVESAN, Flávia. Direitos humanos e o direito constitucional internacional. $11^{\text {a }}$ ed. São Paulo: Saraiva, 2010, p. 121-122. 
de salvaguarda destes direitos que, aos poucos, se tornaram de evidente preocupação e de interesse comum dos Estados ${ }^{26}$.

$\mathrm{E}$, ainda, no cenário de pós-guerra que se desenha o esforço de reconstrução dos direitos humanos como referencial ético a orientar o Direito Internacional, colocando a proteção humanitária como meta global e limitando o poder estatal, evidenciando, assim, que o amparo aos direitos humanos seja, efetivamente, um tema de legítimo interesse internacional. Nesta seara, observam-se duas principais consequências trazidas por conta da nova visão dos direitos desta natureza: a primeira descreve que a tradicional soberania - absoluta do Estado -, inicia um processo de relativização na medida em que são admitidas intervenções no plano nacional em prol do resguardo dos direitos humanos; e a segunda refere-se à solidificação da ideia de que o indivíduo deve ter direitos protegidos na esfera internacional, estando, este, na condição de sujeito de direito ${ }^{27}$.

Prenuncia-se, deste modo, o fim da era em que a forma pela qual o Estado tratava seus nacionais era concebida como um problema de jurisdição unicamente interna - decorrência de sua soberania -, passando a ser compreendido como de importância e interesse internacional. A partir deste marco histórico é que surgem relevantes documentos tratando da matéria de direitos humanos, tendo sido o pioneiro o próprio Direito Humanitário, criado no Século XIX, editando normativas a serem aplicáveis em caso de guerra e/ou conflitos armados, com o objetivo de estabelecer limites à atuação políticoestatal, a fim de assegurar, prioritariamente, o resguardo e o regramento dos direitos desta natureza ${ }^{28}$ quando os Estados que se encontram em zonas de batalha, garantindo, pois, “(...) a proteção para os envolvidos no combate, isto é, militares que foram presos, doentes, feridos e até mesmo os civis que também são vitimados em situações como essas"29.

A nova realidade de proteção dos direitos humanos como ordem internacional ofereceu bases para que o Conselho de Segurança das Nações Unidas (órgão supranacional com capacidade institucional de adotar decisões obrigatórias e vinculativas a todos os Estados-membros da ONU) formulasse entendimento no sentido de trazer exceções ao princípio da não-intervenção, especialmente quando houvessem graves violações de direitos humanos ocorrendo em determinado Estado, e que tais fatos pudessem vir a colocar a paz e a segurança internacional em risco, momento em que se torna oportuno autorizar as intervenções humanitárias com a pretensão elementar de salvaguardar a aludida

26 MAZZUOLI, Valério de Oliveira. Curso de direito internacional público. $4^{\text {a }}$ ed. São Paulo: Revista dos Tribunais, 2010, p. 760.

27 PIOVESAN, Op. cit., p. 123.

28 MAZZUOLI, Op. cit., p. 757.

29 GUERRA, Sidney. Curso de direito internacional público. $7^{\text {a }}$ ed. São Paulo: Saraiva, 2013, p. 469. 
ordem internacional. Convém apontar, ainda, que o Conselho de Segurança é o órgão responsável para determinar as restrições ao uso da força quando este for o único meio capaz de acabar com a ameaça à paz ou à segurança internacional, consoante previsto no artigo 42 da Carta das Nações Unidas ${ }^{30}$.

\section{A ATUAÇÃO INTERVENCIONISTA DAS ORGANIZAÇÕES INTERNACIONAIS NA CONTEMPORANEIDADE}

Registre-se, de pronto, que somente nos Séculos XVI e XVII é que se torna mais visível a figura do Estado tal como conhecido atualmente, pois, devido ao fim das guerras combatidas a partir de canhões e armas de fogo portátil, os líderes estatais foram obrigados a assumir uma postura diferente daquela que vinha sendo aplicada, tendo em vista que a ordem mundial, à época, previa mudanças drásticas no modo de gerir as relações internacionais. Havia, neste caso, a clara noção de que a industrialização provocaria transformações no formato de execução das guerras e de suas respectivas proporções, objetivando, com isso, evitar o declínio do poder governamental e fortalecer a ordem interna nacional. Inicia-se, então, uma fase inovadora chamada de burocracia, em que a força motriz é o regime econômico do capitalismo, o qual visa, por sua vez, o acúmulo de riquezas, o lucro e a manutenção do poder do Estado ${ }^{31}$. $\mathrm{O}$ foco elementar desta sistemática estava em angariar impostos e, assim, proporcionar mais e maiores investimentos em armamentos bélicos.

De certo modo, com o nascimento do Estado Liberal firmado entre os Séculos XVII e XVIII, houve uma mudança na configuração política e jurídica dos Estados que, pautados nas novas aspirações evidenciadas em suas cartas constitucionais, passaram a admitir o princípio da legalidade ${ }^{32}$ e os direitos fundamentais ${ }^{33}$ com plenos limitadores da soberania interna, eis que a relação entre o Estado e os cidadãos deixou de ser aquela dicotomia clássica entre soberano e súdito para se tornar uma clara relação entre sujeitos ${ }^{34}$. Tal ruptura encorajou a formulação da Declaração dos Direitos Humanos e do Cidadão, em 1789, em cujo texto foi consagrado, em seu artigo $3^{\circ}$, “(...) que o princípio de toda a soberania reside essencialmente na nação e que nenhum corpo nem nenhum indivíduo pode exercer autoridade se não emanar expressamente dela" ${ }^{35}$. Nesta seara legislativa internacional,

30 SPIELER, Op. cit., p. 38.

31 MELLO, Op. cit., p. 357-358.

32 Somente é permitida à Administração Pública a prática de atos previstos em lei.

$33 \mathrm{O}$ termo é aplicado àqueles direitos do ser humano, os quais são reconhecidos e positivados na esfera do Direito Constitucional Positivo de um determinado Estado.

34 FERRAJOLI, Luigi. A soberania no mundo moderno: nascimento e crise do Estado nacional. São Paulo: Martins Fontes, 2002, p. 28.

35 BOBBIO; MATTEUCCI; PASQUINO. Op. cit., p. 30. 
atribuiu-se à soberania o caráter de princípio para o desenvolvimento da nação, passando a ser entendida como de observância mútua entre os Estados.

Não obstante existisse a carência de se firmar orientações de política internacional e constitucional frente à tendência pacifista nas relações entre os Estados, continuou-se aceitando a guerra, porém apenas em casos de flagrante defesa e quando houvesse agressão, permitindo, desse modo, circunscrever a soberania do Estado em condições de reciprocidade, com o objetivo de promover a ordem e a paz, mediante a criação de organismos internacionais que tivessem por finalidade a busca constante de tais aspirações, comuns, por certo, a todo o mundo ${ }^{36}$.

Destarte, para se traçar uma linha apropriada de estudo a respeito da temática em tela, é preciso, primeiramente, elucidar, do ponto de vista terminológico, o que se entende por organização internacional, a saber:

(...) pode-se conceituar "organização internacional" como sendo uma associação voluntária de Estados, criada por um convênio constitutivo e com finalidades pré-determinadas, regida pelas normas do Direito Internacional, dotada de personalidade jurídica distinta da dos seus membros, que se realiza em um organismo próprio, dotado de autonomia e especialidade, possuindo ordenamento jurídico interno e órgãos auxiliares, por meio dos quais realiza os propósitos comuns dos seus membros, mediante os poderes próprios que lhes são atribuídos por $\operatorname{estes}^{37}$.

Foi assim que durante o Século XIX os Estados chegaram a claras conclusões de que o novo panorama mundial, concentrado em garantir a observância de interesses tidos por comuns à sociedade internacional, exigia a constituição de órgãos supranacionais ditos permanentes, como é o caso das organizações internacionais (e teria de ser permanentes para assegurar, sobremaneira, a independência e a autonomia da organização frente aos seus Estados-membros), ao invés de se reunirem, de maneira descontínua, em conferências, tais como estavam sendo efetuadas, até então.

Entretanto, a verdadeira mudança paradigmática a respeito foi constatada somente depois de terminada a $1^{\text {a }}$ Guerra Mundial (19141918), momento em que os países pautaram seus esforços na manutenção do estado do bem-estar social (welfare state) como consequência lógica, natural e necessária deste desastroso acontecimento. E justamente neste contexto histórico é que houve um acréscimo considerável no número de organizações internacionais, bem como na utilização de métodos diplomáticos pacíficos a fim de evitar que os possíveis litígios pudessem vir a ser resolvidos por meio da força. No entanto, tais medidas não

36 BOBBIO; MATTEUCCI; PASQUINO. Op. cit., p. 263.

37 MAZZUOLI. Op. cit., p. 553-554. 
foram o suficiente para impedir as atrocidades acometidas pela $2^{\text {a }}$ Guerra Mundial (1939-1945), evento que envolveu a maioria das grandes nações da época, consideradas potências ${ }^{38}$. Conforme ressalta Mello $^{39}$, como resposta às guerras em questão (em especial a segunda), observou-se uma espécie de fenômeno associacionista internacional, que se desenvolveu principalmente nas comunidades européias.

É nesta conjuntura de evidentes mudanças globais que foi assinada, no ano de 1945, na cidade de São Francisco (Califórnia/EUA), a Carta da Organização das Nações Unidas, que trouxe a formação das Nações Unidas (ONU), cujo propósito vem esculpido tanto no Preâmbulo quanto no artigo $1^{\circ}$ de sua carta constitutiva ${ }^{40}$. Dentre as suas principais finalidades estão a de preservar as gerações futuras do flagelo da guerra, reafirmar a fé nos direitos fundamentais do homem, facilitar a cooperação internacional, propiciar o desenvolvimento econômico, o progresso social, os direitos humanos e, sobretudo, a realização e a manutenção da paz mundial, afirmando ser o centro administrativo e político destinado a harmonizar a ação das nações para a consecução

38 A $2^{\text {a }}$ Guerra Mundial foi um conjunto de confrontos bélicos que envolveu cerca de 58 países de várias regiões do planeta. Durante o conflito, formaram-se dois blocos entre as potências beligerantes: Potências do Eixo, formada por Alemanha, Itália e Japão, e Potências Aliadas, constituída por Inglaterra, Estados Unidos da América e União Soviética, além da China, em menor escala, e da França, invadida e ocupada pelos alemães durante quase todo o conflito.

39 MELLO. Op. cit., p. 313.

40 Preâmbulo da carta da ONU: "NÓS, OS POVOS DAS NAÇÕES UNIDAS, RESOLVIDOS a preservar as gerações vindouras do flagelo da guerra, que por duas vezes, no espaço da nossa vida, trouxe sofrimentos indizíveis à humanidade, e a reafirmar a fé nos direitos fundamentais do homem, na dignidade e no valor do ser humano, na igualdade de direito dos homens e das mulheres, assim como das nações grandes e pequenas, e a estabelecer condições sob as quais a justiça e o respeito às obrigações decorrentes de tratados e de outras fontes do direito internacional possam ser mantidos, e a promover o progresso social e melhores condições de vida dentro de uma liberdade ampla. E PARA TAIS FINS, praticar a tolerância e viver em paz, uns com os outros, como bons vizinhos, e unir as nossas forças para manter a paz e a segurança internacionais, e a garantir, pela aceitação de princípios e a instituição dos métodos, que a força armada não será usada a não ser no interesse comum, a empregar um mecanismo internacional para promover o progresso econômico e social de todos os povos. RESOLVEMOS CONJUGAR NOSSOS ESFORÇOS PARA A CONSECUÇÃO DESSES OBJETIVOS. Em vista disso, nossos respectivos Governos, por intermédio de representantes reunidos na cidade de São Francisco, depois de exibirem seus plenos poderes, que foram achados em boa e devida forma, concordaram com a presente Carta das Nações Unidas e estabelecem, por meio dela, uma organização internacional que será conhecida pelo nome de Nações Unidas.” Artigo 1: “Os propósitos das Nações unidas são: 1. Manter a paz e a segurança internacionais e, para esse fim: tomar, coletivamente, medidas efetivas para evitar ameaças à paz e reprimir os atos de agressão ou outra qualquer ruptura da paz e chegar, por meios pacíficos e de conformidade com os princípios da justiça e do direito internacional, a um ajuste ou solução das controvérsias ou situações que possam levar a uma perturbação da paz; 2. Desenvolver relações amistosas entre as nações, baseadas no respeito ao princípio de igualdade de direitos e de autodeterminação dos povos, e tomar outras medidas apropriadas ao fortalecimento da paz universal; 3 . Conseguir uma cooperação internacional para resolver os problemas internacionais de caráter econômico, social, cultural ou humanitário, e para promover e estimular o respeito aos direitos humanos è̀s liberdades fundamentais para todos, sem distinção de raça, sexo, língua ou religião; e 4 . Ser um centro destinado a harmonizar a ação das nações para a consecução desses objetivos comuns. 
das metas enumeradas como comuns ${ }^{41}$.

Muito embora as organizações concebidas no século XX evidenciassem a necessidade de proteção dos objetivos textualmente consolidados na referida Carta, adverte-se que houve um declínio no cumprimento destes por parte da sociedade internacional, haja vista que nos dias de hoje o padrão comportamental se apresenta diverso daquele que se almejou no momento da confecção do documento. Talvez o principal fato seja o de que "(...) os Estados compreenderam que existem certos problemas que não podem ser resolvidos por eles sem a colaboração dos demais membros da sociedade internacional" 42 . Por isso, os países passaram a se apoiar nas organizações internacionais, uma vez que visualizaram nelas a oportunidade de manterem-se no patamar de potências sem precisar de muitos investimentos para seguirem nestas condições de superioridade político-administrativa mundial.

Nesta esteira, acaba-se constatando uma ascensão e uma consequente sobreposição das diretrizes estabelecidas pela Organização das Nações Unidas, eis que, não obstante sua idealização seja originária da vontade dos Estados em estipular uma entidade voltada a assegurar a manutenção da paz e da segurança internacional - atuando unicamente neste campo, isto é, não se envolve em questões domésticas que afligem os países -, não é essa, pois, a conduta que vem sendo observada por parte das Nações Unidas, levando-se a cabo que situações de natureza interna poder ser tomadas como de possível repercussão negativa na esfera das relações internacionais, razão pela qual a organização adota, de imediato, providências com o condão de evitar contradições entre as nações ${ }^{43}$. Porém, tais posturas estão sendo duramente censuradas pelos críticos do Direito Internacional, uma vez que dão margem para que as potências adentrem fortemente na jurisdição dos países, provocando verdadeiras situações de dependência.

Questão relevante a ser mencionada, ainda, é que a Constituição, que para a maioria das nações apresenta-se como sendo sinônimo de ordem ou distribuição de poderes, comporta, também, a sede da soberania e o fim a que se propõe a sociedade civil. Por isso perdese a lógica autônoma quando as organizações internacionais tomam parte nas ingerências e passam a determinar a forma de constituição de um Estado, como, por exemplo, ocorreu com a Iugoslávia, quando “(...) a ONU impôs uma Constituição heterônoma, ou seja, produzida pela comunidade internacional para determinar as bases do direito nacional" ${ }^{4}$. Mesmo que o contexto inicial seja a conservação da paz e a garantia do Direito Humanitário, ainda assim é uma afronta à

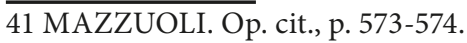

42 MELLO. Op. cit., p. 53.

43 GUERRA. Op. cit., p. 272.

44 VARELLA, Marcelo Dias. Direito internacional público. 2a ed. São Paulo: Saraiva, 2010, p. 241. 
soberania exigir a padronização de normas usando como argumentos o bem maior universal, pois, consoante já esboçava Aristóteles, os artigos constitucionais não servem para todas as oligarquias, nem para todas as democracias, por isso mesmo é que cada Estado carece de ter sua própria normativa fundamental, com o intuito maior de defender os anseios de seus nacionais, levando-se em conta fatores históricos, culturais e regionais.

Pautado nas assertivas acima, alguns doutrinadores atualmente defendem que, na verdade, a ideia pura de Estado se tornou uma mera ilusão, pelo que na concepção jurídica o mesmo sequer existe, e que este vem a ser apenas um instrumento de dominação, representando os interesses de uma determinada classe influente e, consequentemente, dominante $^{45}$. Tais diligências apontam para a aniquilação da autodeterminação ${ }^{46}$ das nações, tendo em vista o surgimento de algo muito mais importante: a "soberania dos mercados" em face da globalização experimentada pelas gigantescas associações de capital que ignoram, por completo, os direitos dos povos e dos Estados ante a necessidade mundial de se romper as cadeias do subdesenvolvimento ${ }^{47}$.

Por vezes, ignora-se que a concretização do princípio de autodeterminação em um mundo onde o exercício da soberania nacional não conhece limites, uma vez que a defesa da independência nacional implica diretamente no uso da força ou, pelo menos, a ameaça de a ele se recorrer como meio para resolver os conflitos entre os países, o que acaba, a posteriori, gerando desigualdade entre eles, a saber:

O grau de independência de cada Estado é definido pelas relações de força que se verificam no sistema político internacional, a distribuição desigual do poder político, no mundo, define uma determinada hierarquia entre os Estados, criando relações hegemônicas eimperialistas exercidas pelos Estados mais fortes sobre os mais fracos ${ }^{48}$.

De acordo com os ensinamentos acima traçados, as relações internacionais não devem ser avançadas mediante decisões derivadas da vontade de um único poder soberano que dita normas sob outro, pois isso faz com que os Estados recorram, como última opção, à prova

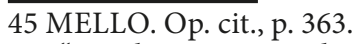

46 "Geralmente entende-se por Autodeterminação ou autodecisão a capacidade que populações suficientemente definidas étnica e culturalmente têm para dispor de si próprias e o direito que um povo dentro de um Estado tem para escolher a forma de Governo. Pode portanto distinguir-se um aspecto de ordem internacional que consiste no direito de um povo não ser submetido à soberania de outro Estado contra sua vontade e de se separar de um Estado ao qual não quer estar sujeito (direito à independência política) e um aspecto de ordem interna, que consiste no direito de cada povo escolher a forma de Governo de sua preferência". BOBBIO; MATTEUCCI; PASQUINO. Op. cit., p. 70.

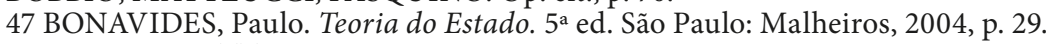

48 BOBBIO; MATTEUCCI; PASQUINO. Op. cit., p. 802. 
de força, em vista do possível desenrolar das situações postas em debate, fazendo, desta maneira, com que os governos estatais armem-se, uns contra os outros ou, se acaso não possuírem defesa própria, apoiar-se-ão, por conseguinte, em armas alheias ${ }^{49}$. Tais medidas seguramente geram circunstâncias de absoluta subordinação das nações mais desprovidas aos países que se mostram interessados justamente em fornecer o armamento necessário para "equilibrar" a contenda.

Percebe-se, pois, que apesar de as organizações internacionais defenderem a existência da livre apreciação das normas internacionais por parte dos Estados, ainda assim contata-se que a distância entre o fato e o direito mostra-se cada vez maior. A criação de certas regras internacionais, bem como o funcionamento das próprias organizações, é remanescente do passado de monopólio, e tão-somente persistem por continuarem assentadas em princípios como a igualdade, a independência e até mesmo na própria soberania. Para tanto, as propriedades atribuídas aos sujeitos de Direito Internacional são muito afastadas de suas características reais, ao passo que a atuação das organizações vem, irremediavelmente, comprometendo os institutos da soberania e da independência da grande maioria dos Estados em vista da desigualdade que, de fato, reina entre as potências ${ }^{50}$.

Neste viés de debate quanto à legitimidade e à ação democrática na elaboração de normas internacionais, faz-se apropriada a crítica argumentativa a seguir transcrita:

Ora, o que ocorre atualmente é que os Estados mais poderosos, apesar de em minoria, elaboraram e elaboram as normas internacionais ainda "em vigor" e lutam pela sua manutenção. Na verdade, o processo de formação das normas internacionais não é, via de regra, democrático, vez que ele leva em consideração o poderio dos Estados ${ }^{51}$.

Os Estados subdesenvolvidos ou em vias de desenvolvimento têm sofrido, hodiernamente, com o processo de internacionalização que conduz a uma fragmentação das identidades culturais à medida que a distinção se tornou a marca do desconforto perante a carência de padronização do comportamento humano ${ }^{52}$. Neste norte, é possível averiguar que a noção plena de soberania é a que mais padece com as transformações em questão, pois está sendo fortemente alterada frente às múltiplas experiências que os Estados suportaram ao longo dos anos. A ordem internacional tem manipulado e submetido a condição humana a fim de organizar a coletividade e impedir eventuais crises,

49 Ibíd., p. 1089.

50 MERLE, Marcel. Sociologia das relações internacionais. Brasília: Editora UnB, 1981, p. 35.

51 MELLO. Op. cit., p. 59.

52 MERLE. Op. cit., p. 141-143. 
impondo limites à sua ação governamental ${ }^{53}$.

Vislumbra-se, portanto, que os interesses fundamentais das sociedades em geral transmutaram bruscamente ao decorrer do tempo, sendo manifestamente evidente que aqueles tidos como principais, hoje em dia, são os de cunho prioritariamente econômico. Mesmo com os ditames inovadores de universalização de condutas focadas na salvaguarda dos direitos humanos, cada Estado tem defendido exaustivamente seus próprios interesses perante todos os demais. Observa-se, neste cenário, que perdura, ainda, a lei do individualismo a despeito da proliferação das organizações internacionais, e que tal postura ganhou vigor e dinamismo com a expansão do sistema capitalista, permitindo, com isso, a manutenção da estrutura desenvolvimentista das potências. Neste diapasão, Marcel Merle apresenta uma ponderada reflexão ao debate sugerido acima, conforme segue:

A maioria dos países subdesenvolvidos pertencem a regimes que foram colocados sob controle das grandes potências pelo prisma do regime colonial. Assim acontece na América Latina (emancipada desde o início do século XIX), na maior parte do sudeste asiático, no Oriente Médio e no continente africano, não falando da China que foi durante um meio século submetida à tutela das grandes potências ${ }^{54}$.

Com o término da $2^{\text {a }}$ Guerra Mundial, muitos territórios que estavam sob a administração estrangeira readquiriram ou recobraram sua soberania, todavia, a conquista de suas respectivas independências não se mostrou como sinônimo de imediata prosperidade social e econômica, prosseguindo, por determinado tempo, imbuídos de diversas dificuldades, tais como a pobreza, a fome, decorrentes da escassez de trabalho e da destruição das terras de plantio ${ }^{55}$. Como solução, os Estados buscaram abrigo nas organizações internacionais, porque estas continham os meios deles participarem ativamente nas relações internacionais. Para tanto, "o Direito Internacional não os auxiliou na luta contra o colonialismo e tem sido um grande aliado no estabelecimento do neocolonialismo" ${ }^{56}$. Os países não haviam se preparado para uma correção de rumos nas relações internacionais e foram sacudidos pelo capitalismo, o que provocou um choque inesperado no mercado, impedindo que se desvencilhassem da intervenção das potências no caráter social interno.

As recomendações preconcebidas nas relações internacionais insistiam na reforma das atitudes de alguns Estados diante da assertiva

53 MELLO. Op. cit., p. 59-63.

54 MERLE. Op. cit., p. 178.

55 Ibíd., p. 178.

56 MELLO. Op. cit., p. 60. 
dos novos temas globais, dentre eles o meio ambiente, os direitos humanos, o desarmamento e a solução de conflitos, tendo sido debatidos e, posteriormente obtidos, por intermédio de insumos progressistas através de tratados celebrados entre nações, tomando-se em conta a cooperação bilateral e as decisões multilaterais. Entretanto, as idéias e os padrões de condutas - internas e internacionais - exigiam aplicação de recursos econômicos e de melhoria nas questões sociais, além de alteração cultural. Muitas nações não se encontravam preparadas para esta drástica mudança, e as potências aproveitaram o momento para desenvolver as políticas de assistência externa ${ }^{57}$, compreendida, de mais a mais, como sendo uma operação de vantagem, fundada em transações comerciais puramente econômicas ${ }^{58}$.

Hoje em dia a figura da assistência externa tem servido habilmente para estabelecer e auxiliar no progresso do neocolonialismo ${ }^{59}$, e em contrapartida, para promover o aniquilamento da soberania. A expressão assistência externa comporta ambiguidade, pois não se trata de mera doação assistencial de bom grado, mas de um encargo àqueles que as recebem, senão quando categoricamente dotadas de segundas intenções em relação à sua pretensão original, como é o caso, por exemplo, dos Estados Unidos da América, que economizaram com as despesas de estocagem enviando alimentos para outros países, ou, na hipótese do Brasil, Argentina, Chile e México, que já enviaram ao exterior, sob a forma de juros e de remessa de lucros, mais do que receberam. Tais condutas têm acarretado, e muito, no endividamento das nações em vias de desenvolvimento ${ }^{60}$. Ao que parece, este tipo de postura acaba contribuindo ou abrindo margem para a execução de uma série de assistências militares mascaradas de "intervenções humanitárias".

Neste viés, os países ricos assumem, oportunamente, o que se convencionou chamar de "dever de ingerência", uma vez que não existem parâmetros e/ou fórmulas universalmente aceitas ou prescritas como o procedimento modelo para a correta execução de "assistências

57 Refere-se a atuação de ajuda por parte dos países estrangeiros e organizações internacionais, com o fim de possibilitar que os países em desenvolvimento concretizem seus objetivos fundamentais de promoção do bem-estar do povo. Entretanto, a assistência externa (internacional) tem sido desestimulada pelas Nações Unidas, alertando aos “(...) Estadosmembros da Organização e às instituições especializadas que se abstenham de prestar assistência aos Estados que praticam uma política colonial (...)”. BOBBIO; MATTEUCCI; PASQUINO. Op. cit., p. 72.

58 ALBUQUERQUE, José Augusto Guilhon. "Os desafios de uma ordem internacional em transição”. In: ALTEMANI, Henrique; LESSA, Antônio Carlos (ed.). Relações internacionais do Brasil: temas e agendas. São Paulo: Saraiva, 2006, p. 44-45.

59 "O neocolonialismo caracteriza-se hoje, mais que pelo domínio político exclusivo de uma metrópole sobre as suas antigas possessões coloniais, pelo domínio do mercado capitalista internacional sobre países produtores de matérias-primas, privados de estruturas industriais integradas, dependentes financeira e tecnologicamente, e governados por classes políticas profundamente condicionadas pela estrutura da dependência econômica." BOBBIO; MATTEUCCI; PASQUINO. Op. cit., p. 181.

60 MELLO. Op. cit., p. 368-369. 
externas", dando abertura, portanto, a abusos políticos e econômicos travestidos de "condutas humanitárias". Ficam, então, e pelo alto grau de subjetividade intrínseco na questão, a critério de qualquer instância capaz de sancionar quais são os direitos e os valores globais, bem como acusar, julgar e indicar os eventuais culpados que porventura venham a desrespeitar estes direitos. Com isso, cria-se uma tendência de adoção de padrões estabelecidos por algumas nações que supostamente tiveram maior progresso sócio-comportamental em detrimento de outras ditas menos "humanitárias" 61.

Por derradeiro, nota-se que a aparente falta de normatização que indique as regras, as formas e os momentos apropriados para uma nação ou organização internacional intervir nas ações ou omissões de um determinado país dificulta, sobremodo, a atribuição da legitimidade às investidas (intervenções) militares, principalmente aquelas fundadas em ajuda humanitária, uma vez que é clara a idéia de que existem questões de interesses econômicos, regionais e comerciais atreladas à estas operações de paz que podem, lamentavelmente, desvirtuar o verdadeiro intuito, primordial à defesa e à proteção dos civis, ou mesmo de outras potenciais vítimas de um conflito armado.

\section{CONCLUSÃO}

Diante do conteúdo explanado, observa-se que quando as perspectivas da coletividade humana tomam amplitude significativa, a ordem jurídica mundial procura se adequar aos desdobramentos naturais. Neste contexto, o Direito Internacional evoluiu junto à sociedade, sem qualquer planejamento inicial, mas fortalecido principalmente em decorrência das consequências deixadas pelos conflitos e pelas guerras que assombraram por muito tempo os países. Devido a isso, os governos, através de modernos diálogos políticos interestatais, foram convertendo em ruínas os pensamentos retrógrados da civilização primitiva, passando a criar metas, focados em se tornarem os verdadeiros protagonistas de uma inovadora cadeia internacional pautada na mútua cooperação, buscando-se com isso, e de forma específica, o alcance da paz mundial.

Com o passar dos anos, os Estados conseguiram compreender que seria preciso alterar as antigas conjunturas, concentrando-se em alternativas universalistas, pretendendo justificar a predominância de imposição de uma ordem com base na criação de planos de ação, norteados, segundo critérios racionais universais, em que propositalmente - e consequentemente - acaba excluindo os interesses setoriais, tendo em vista que o direcionamento das nações estaria centralizado na concepção de políticas externas para o favorecimento de uma parcela das potências estatais.

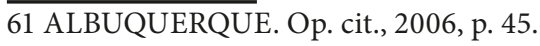


As realidades contemporâneas apresentam especificidades que expõe a contradição entre a dimensão alcançada pela globalização e os sistemas políticos hodiernamente existentes em todas as partes do mundo. As disparidades entre os Estados com relação à riqueza, o poder e a segurança são marcantes e visíveis, e os que detêm mais harmoniosamente este conjunto de aparatos é que estão tomando a dianteira nas decisões mundiais.

Entretanto, a força que traz a independência aos Estados é a soberania nacional, sendo entendida como o princípio que confere uma série de poderes e atribuições aos governos. Todavia, no decorrer do estudo observou-se que a partir do Século XX tal instituto passou a enfrentar um processo de esvaziamento, sendo referida situação acentuada por ações equivocadas dos próprios países. Neste ínterim, não cabe mais falar em uma soberania absoluta, eis que a soberania, em sua acepção mais clássica, vem sofrendo notáveis alterações na medida em que os Estados reduzem suas atribuições, especialmente com o advento da causa humanitária presente no cenário internacional como de observância obrigatória por parte dos principais atores de Direito Internacional Público.

Ademais, e por derradeiro, existe uma eminente necessidade de se eliminar o protecionismo que as potências estatais e as organizações internacionais oferecem aos Estados envolvidos em conflitos civis, pois tal comportamento carrega uma profunda característica de futura dependência comercial, industrial e político-normativa, levando-se em consideração que os conceitos de soberania nacional e de solidariedade na política externa são faces opostas da "mesma moeda" que convergem para a aniquilação da verdadeira essência da proteção aos direitos humanos.

\section{RESUMO BIOGRÁFICO}

Luiz Fernando Vescovi é Professor titular de Direito Internacional Público da Universidade do Oeste de Santa Catarina Campus Videira. Mestre em Direito Internacional pela Universidad San Carlos. Mestrando em Direito das Relações Internacionais e da Integração na América Latina pela Universidad de la Empresa. MBA em Comércio Internacional pela Faculdade de Tecnologia Internacional. Especialista em Geopolítica e Relações Internacionais pela Universidade Tuiuti do Paraná. Autor de livros jurídicos e artigos científicos. Advogado.

Anatieli Aparecida Fiabane é Especialista em Direito Notarial e Registral pela Damásio Educacional. Bacharel em Direito pela Universidade do Oeste de Santa Catarina Campus Videira. Autora de livro jurídico e artigos científicos. Escrevente Notarial Sênior do Tabelionato de Notas e Protestos de Videira/SC. 


\section{REFERÊNCIAS BIBLIOGRÁFICAS}

ALBUQUERQUE, José Augusto Guilhon. "Os desafios de uma ordem internacional em transição". In: ALTEMANI, Henrique; LESSA, Antônio Carlos (ed.). Relações internacionais do Brasil: temas e agendas. São Paulo: Saraiva, 2006.

ARISTÓTELES. Política. 3a ed. Brasília: Editora UnB, 1997.

AZAMBUJA, Darcy. Teoria geral do Estado. 4a ed. São Paulo: Globo, 2008 .

BOBBIO, Norberto; MATTEUCCI, Nicola; PASQUINO, Gianfranco. Dicionário de política. 11ª ed. Brasília: Editora UnB, 1998.

BONAVIDES, Paulo. Teoria do Estado. 5a ed. São Paulo: Malheiros, 2004.

BULL, Hedley. A sociedade anárquica: um estudo da ordem na política mundial. São Paulo: Clássicos IPRI, 2002.

DALLARI, Dalmo de Abreu. Elementos de teoria geral do Estado. 30a ed. São Paulo: Saraiva, 2011.

FERRAJOLI, Luigi. A soberania no mundo moderno: nascimento e crise do Estado nacional. São Paulo: Martins Fontes, 2002.

FILOMENO, José Geraldo Brito. Manual de teoria geral do Estado e ciência política. $5^{\text {a }}$ ed. Rio de Janeiro: Forense Universitária, 2003.

GRAMSCI, Antonio. Maquiavel, a política e o Estado moderno. $7^{\mathrm{a}}$ ed. Rio de Janeiro: Civilização Brasileira, 1989.

GUERRA, Sidney. Curso de direito internacional público. $7^{\text {a }}$ ed. São Paulo: Saraiva, 2013.

HOBBES, Thomas. Leviatã ou matéria, forma e poder de um Estado eclesiástico e civil. São Paulo: Abril Cultural, 1974.

KANT, Immanuel. A paz perpétua: um projeto filosófico. Covilhã: Universidade da Beira Interior, 2008.

KISSINGER, Henry. Ordem mundial. Rio de Janeiro: Objetiva, 2015.

MAZZUOLI, Valério de Oliveira. Curso de direito internacional público. $4^{\text {a }}$ ed. São Paulo: Revista dos Tribunais, 2010.

MELLO, Celso D. de Albuquerque. Curso de direito internacional público. $15^{\mathrm{a}}$ ed. Rio de Janeiro: Renovar, 2004. 
MERLE, Marcel. Sociologia das relações internacionais. Brasília: Editora UnB, 1981.

NIETZSCHE, Friedrich. Humano, demasiado humano: um livro para espíritos livres. São Paulo: Companhia das Letras, 2008.

ORTEGA Y GASSET, José. A rebelião das massas. Brasília: Ruriak Ink, 2013.

PIOVESAN, Flávia. Direitos humanos e o direito constitucional internacional. $11^{\text {a }}$ ed. São Paulo: Saraiva, 2010.

ROSA, Leonardo Sérgio Cesar Lopes Moreira. "Poder constituinte controlador: uma solução diplomática aos conflitos de grandes proporções". Conteúdo Jurídico. [acesso em: 21 fev. 2016]. Disponível em: <http://www.conteudojuridico.com.br/artigo,poder-constituintecontrolador-uma-solucao-diplomatica-aos-conflitos-de-grandesproporcoes, $46572 . \mathrm{html}>$

SPIELER, Paula Bartolini. "A indeterminação do conceito de intervenção humanitária: reflexo no caso Timor Leste”. [Dissertação de Mestrado em Relações Internacionais]. Pontifícia Universidade Católica do Rio de Janeiro, Rio de Janeiro, 2007.

VARELLA, Marcelo Dias. Direito internacional público. $2^{\text {a }}$ ed. São Paulo: Saraiva, 2010.

VATTEL, Emer de. O direito das gentes. Brasília: Editora UnB, 2004.

ZANCANARO, Antonio Frederico. A corrupção político-administrativa no Brasil. São Paulo: Editora Acadêmica, 1994.

ZIZEK, Slavoj. Violência: seis reflexões laterais. São Paulo: Boitempo, 2014. 